\title{
Assessment of Knowledge Attitude and Practice towards Solid and Liquid Waste Management among Addis and Kometa Kebele Community Mizan-Aman Town, Bench - Maji Zone, Snnpr, South Waste Ethiopia, 2017
}

\author{
Sisay Shewasinad ${ }^{1}$, Tariku Daniel ${ }^{2}$, Hawi Abebe ${ }^{2}$, Nardos Tsegaye $^{2}$ and Tesfaye Abera ${ }^{1 *}$ \\ ${ }^{1}$ Lecturer at Department of nursing, Mizan-Tepi University, Ethiopia \\ ${ }^{2}$ Department of nursing, Mizan-Tepi University, Ethiopia
}

Received: September 28, 2017; Published: October 12, 2017

*Corresponding author: Lecturer at Department of nursing, College of health science, Mizan-Tepi University, Ethiopia

Abstract

Background: Waste is defined as unwanted remains, residues discarded, and material or by products which are no longer required by the initial user. These materials are by-products of human activities such as process of preparation, manufacture, packing, repacking, unpacking, construction, renovation of structures and mining operations. Almost any substance that is discarded is designated as waste, but it may also be considered as a potential resource. Virtually everything in the "waste stream" has residual value for someone or some business in the community. Waste can serve as valuable resources as ground cover to reduce erosion, fertilizer to nourish the crops. KAP studies investigate the knowledge attitude and practice of respondents on the particular subject of interest. KAP studies tell us what people know about certain things, how they feel, and how they behave. The knowledge possessed by a community refers to their understanding of waste generation, description and recycling in this context. Attitude refers to their feeling toward waste separation, collection as well as recycling. Practice refers to the way in which they demonstrate their knowledge and attitude throw their actions.

Objective: Assessment of the knowledge, attitude and practice of Addis and Kometa kebele community towards waste disposal management in South West Ethiopia, 2017.

Methodology: A descriptive cross-sectional design and systematic sampling technique was used to assess liquid and solid waste disposal management in Mizan-Aman Town community. Data was collected from 392 selected samples and was tallied manually, processed and analyzed in a line of its objective by using manual tally and table of frequency. Data quality was assured by performing pre-test to evaluate the appropriateness of data collection instrument.

Result: The finding of this study showed that majority $84 \%$ of the respondents were females, regarding their ethnicity $35.5 \%$ were Bench, also majority of the participants(87.1\%) were married with regard to their religion (47\%) were Orthodox, on the other hand $48.6 \%$ of the respondents were the age between $21-30$. Furthermore, the study showed that $81.8 \%$ of the respondents have good knowledge, $77.5 \%$ of the participants showed positive attitude toward waste management as well as $76.9 \%$ of participants have good practice to ward waste management.

Conclusion and Recommendation: The finding of the study revealed that majority of Mizan-Aman town community have good level of knowledge, have positive attitude and showed good practice to ward waste management.

A. The Mizan-Aman town municipality was recommended to prepare pits/ditches in the town in sufficient quantity for solid waste disposal.

B. Mizan-Aman town community has best knowledge, positive attitude and good practice so Mizan-Aman Municipality, Addis and Kometa kebele administrators and health extension workers should do more to ensure the sustainability of this trend as well as to aware $100 \%$ of community.

C. Further detailed studies were recommended for intervention by using this high light for further interventions. 


\section{Introduction}

\section{Back ground}

Waste is defined as unwanted remains, residues discarded and material or by products which are no longer required by the initial user. These materials are by-products of human activities such as process of preparation, manufacture, packing, repacking, unpacking, construction, renovation of structures and mining operations. Almost any substance that is discarded is designated as waste, but it may be considered as a potential resource. Virtually everything also in the "waste stream" has residual value for someone or some business in the community. Waste can serve as valuable resources as ground cover to reduce erosion, fertilizer to nourish the crops and the source of energy etc [1].

The management of waste should focus on how to find the value and redirect it back to the community. But unfortunately, our collecting and dumping process mix and crush everything together; and make separation an expensive and sometimes impossible task to properly manage wastes [2]. The proper management of solid wastes generated from individual house, institutions such as hospitals, health centers; from public eating and drinking establishments (hotels, restaurants etc.); from business and working places is a very important part of environmental health service in a community. If these wastes are not disposed in a proper way, they create breeding places for insects such as flies, mosquitoes etc; they provide food and harborages for rats. These insects and rats are health risk in that they are potential disease transmitters. In addition to health problems rats also imposes an economic problem [3].

The seriousness of environmental depletion in Ethiopia reveals the relationship between natural environment and people are unfriendly. Thus it seems it will require high time to take urgent actions by modifying people life style, making people an experienced of sustainable development by acquiring appropriate environmental knowledge, knowhow, skills and capacities [4] millions more [5-7]. Improved sanitation attributes to $36 \%$ reduction in risk of diarrhea while hand washing with soap reduces the risk of diarrhea by $48 \%$ [8]. In addition, good hygiene practices improve overall health through reduced rates of pneumonia, scabies, skin and eye infections, and influenza [9]. Hand washing is also associated with lower respiratory infection [10]

The seriousness of environmental depletion in Ethiopia witness as that the relationship between natural environmental and people are un friendly Thus it seems high time to take urgent actions by redressing people life style, people an experience sustainable developmental by acquiring appropriate environment knowledge, knowhow, skills and capacities [4].

\section{Statement of the Problem}

Globally, 2.6 billion people or 39 percent of the world population do not use improved sanitation. Some 1.1 billion people still defecate in the open air. Ten countries, including Ethiopia are home to 81 percent of them. Open defecation is largely a rural phenomenon, most widely practiced in Southern Asian and SubSaharan Africa. At current rates of progress, the world will miss the
MDG sanitation target by almost 1 billion people. The magnitude of the hygiene challenge also remains. Waste management is a critical issue worldwide. Open unregulated dumps are still the predominant methods of waste disposal in most developing countries [1]. Sanitation is fundamental to human development and security. The combined effects of inadequate sanitation, unsafe water supply and poor personal hygiene is responsible for 88 percent of childhood deaths from diarrhea. Every year, the failure to tackle these problems claims the lives of 1.5 million children and results in severe welfare losses - wasted time, reduced productivity, ill-health, impaired learning, environmental degradation and lost opportunities [5-7].

Improper waste management may have health, environmental and economic problems. Ecological phenomena such as water, soil, and air pollution have been attributed to improper management of solid wastes. The U.S public health service has published the result of the study tracing the relationship of 22 diseases to improper solid waste management. Waste water is the cause of enteric communicable diseases. Human excreta contain disease causing organisms, thus it is the source of many infections [11-13].

In Sub- Saharan Africa, 69 percent of the population does not have access to improved sanitation facilities. At the current rate of progress, the sanitation MDG will not be met for a long time. Although difficult to predict using current models, some suggest it may even be as late as2076 [10,14]. Waste management is a growing public concern in Ethiopia [15]. In many cities of the country, waste management is poor and solid wastes are dumped along roadsides and into open areas, endangering health and attracting vermin [16]. Access to sanitation is also among the lowest in the world. Sixty percent of the population still practices open field defecation. Only 12 percent (8\% in the rural and $29 \%$ in the urban) of the population use improved sanitation facilities. Urban households are more than three times as likely as rural households to have access to improved (12 toilet Facilities).

It is impossible to understand the magnitude and severity of existing and potential problem of the study area due to lack of previously conducted research around the area. However, studies conducted by Research Inspired Policy and Practice Learning in Ethiopia and the Nile Region (RIPPLE) in the SNNPR indicate a substantial increase in the number of household latrines since the deployment of Health Extension Workers. It shows an increase in a few years, from $16 \%$ to $94 \%$ coverage in Mirab Abaya Woreda and $10 \%$ to $69 \%$ in Alaba Special Woreda. Nevertheless, these studies indicate hand washing facilities and practice to be still poor [17]. Lack of provisions to proper sanitation facilities can hinder the development of a country. This may be a challenge to achieve Millennium development goal Provision of adequate sanitation facilities is not only socioeconomic and developmental issue, but also an issue of self-respect, human dignity and public health [18].

Rapid growth of urban population and solid waste management are some of the main challenging problems for developing countries and the waste disposal habit of the Community causes the deterioration of the environment [19]. As a result, since Ethiopia is one of the developing countries, the urban areas have 
problem of solid Waste management, which has its own negative impact on the environment. For Instance, the study conducted on assessment of Dessie town, revealed that improper and insufficient solid waste management is causing serious Environmental and sanitary problems [20].

Similarly, the study conducted on assessment of solids waste management of Addis Ababa city discussed that, from the solid waste generated per day only 65 percent is collected as municipal waste and the remaining 35 percent of the waste is disposed off through informal means except smaller percentage going to incineration and dumped on open sites, drainage, channels, rivers and valleys as well as on the streets. A simple observation around riverbank indicates large percentage of the uncontrolled waste goes to the rivers [21]. Similarly, forwarded that uncollected garbage is serious environmental hazard for all urban centers of the country, especially in urban areas where the roads within the town or city are not accessible for collection by municipality and these cause bad smells and attract various disease vectors and pests resulting in low aesthetic quality of the towns [22]. There is no concrete data that show level of solid and liquid waste disposal management and KAP of local population for possible intervention. The main intention of this research was assessing the KAP of the Addis and Kometa kebele community to ward waste disposal.

\section{Literature Review}

\section{Knowledge of House Hold on Waste Management}

A research assessment that took place on Malaysia City stated that, despite the high status of awareness expressed by 64 percent of the student concerning solid waste Management, it is not consistent with their attitude and perception. The result of the study showed that more than half of the students (65.9\%) have negative attitudes towards solid waste management [23] (Tables $1 \&$ 2).

Table 1: Socio-demographic characteristics of respondents, Addis and Kometa kebele, June, 2017.

\begin{tabular}{|c|c|c|c|}
\hline & Variables & Frequency & Percentage \\
\hline \multirow{3}{*}{ Age } & $15-20$ & 27 & 6.9 \\
\hline & $21-30$ & 183 & 48.6 \\
\hline & $>30$ & 178 & 44.5 \\
\hline \multirow{2}{*}{ Sex } & Male & 62 & 16 \\
\hline & Female & 226 & 84 \\
\hline \multirow{4}{*}{ Religion } & Muslims & 64 & 21.6 \\
\hline & Orthodox & 185 & 47.9 \\
\hline & Protestant & 120 & 25.5 \\
\hline & Catholic & 19 & 5 \\
\hline \multirow{5}{*}{ Ethnicity } & Bench & 138 & 35.5 \\
\hline & Kefa & 96 & 24.8 \\
\hline & Amhara & 84 & 21.6 \\
\hline & Oromo & 37 & 9.5 \\
\hline & Others & 35 & 9 \\
\hline \multirow{3}{*}{ Marital status } & Married & 338 & 87.1 \\
\hline & Single & 40 & 10.4 \\
\hline & Widowed & 10 & 2.6 \\
\hline \multirow{5}{*}{ Marital status } & Illiterate & 82 & 21.2 \\
\hline & Read and write & 102 & 26.3 \\
\hline & Elementary & 60 & 15.5 \\
\hline & High school & 74 & 18.6 \\
\hline & Diploma and above & 70 & 18 \\
\hline \multirow{3}{*}{ Occupational status } & Government employee & 71 & 18.3 \\
\hline & Merchant & 163 & 41.9 \\
\hline & House wife & 154 & 39.6 \\
\hline \multirow{2}{*}{ Monthly income of respondents } & $>3500$ & 78 & 20.1 \\
\hline & Unknown & 310 & 79.9 \\
\hline
\end{tabular}

Table 2: Participants response on the knowledge question, Addis and Kometa kebele community, June, 2017.

\begin{tabular}{|c|c|c|c|}
\hline \multirow{2}{*}{ Do you know what waste mean } & & Frequency \\
\cline { 2 - 4 } & Yes & 388 & 100 \\
\hline
\end{tabular}




\begin{tabular}{|c|c|c|c|}
\hline \multirow{2}{*}{$\begin{array}{l}2 \text { If yes for question number } 1 \text { what } \\
\text { is waste state }\end{array}$} & Useless materials & 303 & 78 \\
\hline & Sweepings from house & 85 & 22 \\
\hline \multirow{2}{*}{$\begin{array}{c}3 \text { Do you know that if solid and } \\
\text { liquid wastes are not managed well } \\
\text { cause for generation of different } \\
\text { infectious disease }\end{array}$} & Yes & 388 & 100 \\
\hline & No & 0 & 0 \\
\hline \multirow{2}{*}{$\begin{array}{l}\text { Do you know that if solid wastes are } \\
\text { properly managed they can be used } \\
\text { for further other purpose }\end{array}$} & Yes & 192 & 50.5 \\
\hline & No & 196 & 49.5 \\
\hline
\end{tabular}

Study done in city of Gweru in Zimbabwe has shown that the most common method used to dispose the waste is through open dumping of waste by 383 (65\%) out of the total of 589 enterprises and burning of waste is the second most popular method of disposing the waste as reported by 131 (22\%) of the enterprises. The factors that were cited as influencing open dumping of solid waste are these include lack of solid waste disposal facilities (50\% of the enterprises), the nonexistence of penalties for dumping, lack of enforcement of legal deterrents by way of penalties $(25 \%$ of the enterprises), inadequate information on waste disposal and management in general ( $22 \%$ of the enterprises), and the desire to save on disposal costs as shown in Table 3.

Table 3: Attitude assessing questions and their respective answers, Addis and Kometa kebele, June,2017.

\begin{tabular}{|c|c|c|c|}
\hline & Variables & Frequency & Percentage \\
\hline \multirow{2}{*}{$\begin{array}{l}\text { Proper waste management has } \\
\text { health environmental and ecologic } \\
\text { important }\end{array}$} & Strongly agree & 388 & 100 \\
\hline & Strongly disagree & 0 & 0 \\
\hline \multirow{2}{*}{$\begin{array}{l}\text { Every person does have the } \\
\text { responsibility for the proper } \\
\text { collection and disposal of waste }\end{array}$} & Disagree & 208 & 53.6 \\
\hline & Agree & 180 & 46.4 \\
\hline \multirow{2}{*}{$\begin{array}{l}\text { Solid and liquid wastes should not } \\
\text { be collected to gather }\end{array}$} & Strongly agree & 155 & 40 \\
\hline & Agree & 233 & 60 \\
\hline \multirow{2}{*}{$\begin{array}{l}\text { Solid and liquid wastes can be } \\
\text { recycled for re use }\end{array}$} & Agree & 248 & 72.1 \\
\hline & Disagree & 140 & 27.9 \\
\hline
\end{tabular}

A total of $292(50 \%)$ respondents identified absence of municipal solid waste management facilities as the key factor responsible for open dumping of waste in the informal sector enterprises. The enterprises that reported that lack of facilities promoted open dumping of waste included the service sector (63\% operators), the retail sector $(50 \%)$, the repair sector ( $49 \%$ operators), the manufacturing ( $45 \%$ operators), and the construction sector $(39 \% 0$ operators.

The informal sector enterprises, 191 (32\%) respondents indicated that they would source-reduce waste and 296 (50\%) of the respondents indicated that they would prefer to recycle waste and hence a total of $487(82 \%)$ respondents were considered the potential "reducers-recyclers" in the informal sector of Gweru. Waste minimization is the most dominantly preferred in the service sector (57\%) and it is the second most dominant way of managing waste in the retail enterprises (35\%), the repair (20\%), the manufacturing (26\%), and the construction (25\%) enterprises. On the other hand, recycling dominates as a preferred method of waste management in construction (70\%), repair (68\%) manufacturing, and retail enterprises (45\%) [24]. The study conducted on assessment of students' awareness of and views about solid waste management in Gurage Zone, Wolkite town showed that, A views about the role of musicality on solid waste disposal, Accordingly, of 351 students, only 106 (30.2\%) supported the view that the Wolkite town municipality is well organized to execute its responsibility.
In addition, half of male and $41.4 \%$ female respondents agreed with the view that Wolkite town municipality could be blamed for not inviting any private or non-governmental organizations to involve on solid waste management, only $17.5 \%$ male and $23.6 \%$ female respondents did not agree with the same view. While about $32.2 \%$ male and $35 \%$ female respondents are unable to decide. This might be due to shortage of information about municipality solid waste management.

On the other hand, significant difference has been observed between the two groups regarding the opinion that "the Wolkite town municipality does not have controlling mechanism to protect the public against those who are dumping solid waste everywhere" with female students showing favorable view than males $(\mathrm{p}=$ 0.042 ). While with no statistical difference between the two groups, $78.6 \%$ of the students agreed with the view that the existing method (Donkey pulling trolley) being used by the municipality for solid waste transportation could not cover the whole town [25].

\section{Attitudes of the Community on Waste Management}

Study conducted in one town of Thailand reveled that around three-quarters (77.8\%) highly intended to dispose of recyclable waste into separate specific waste bins. Twelve point two percent had a moderate intention while only $10.0 \%$ had a low intention to dispose of recyclable materials into separate waste bins. Nearly all of them (92.2\%) showed a good attitude to separately dispose 
of recyclable materials while $5.6 \%$ showed a moderate attitude and only $2.2 \%$ showed a bad attitude. Nearly three-quarters (73.3\%) presented good subjective norms to separately dispose of recyclable materials while about a quarter $(24.4 \%)$ presented moderate subjective norms and only 2.2 presented bad subjective norms. The majority (87.8\%) had high perceived behavioral control to separately dispose of recyclable materials while only $4.4 \%$ and $7.8 \%$ had moderate and low perceived behavioral control, respectively [26].

\section{Practice Communities Based Waste Management}

Study from Thailand indicates that in estimation 24.73 million tons of municipal solid waste was generated in the year 2012. Only $15.90 \mathrm{~m}$ tons (64.29\%) was disposed of in prepared waste bins and $11.90 \mathrm{~m}$ tons was collected. Therefore, more than half of the waste (13.62 $\mathrm{m}$ tons or $55.08 \%)$ was untreated or incorrectly treated [27]. A study done on domestic solid waste disposal methods in Lagos metropolis, Nigeria has shown that there are six major disposal methods were common in the study area. The use of accredited private sector participation (PSP) accounted for $25.9 \%$ of disposal methods in high, $26.1 \%$ in the medium, and $38.6 \%$ in the low density areas. Similarly, as a form of social service and environmental management initiative provided by the Lagos State Government, $16.2 \%, 10.5 \%$, and $27.2 \%$ of the residents in the high, medium, and low densities, respectively, indicated that they often disposed their solid waste in Lagos State Waste Management's (LAWMA) refuse facility.

Despite the above findings, the study still established that indiscriminate waste disposal was prevalent in Lagos metropolis. This assertion is premised on the fact that $(21.9 \%, 21.1 \%$, and $22.7 \%$ ) of the residents disposed solid waste on the road in the high, medium, and low densities, respectively: a proportion as high as $16.5 \%$ and $18 \%$ of the residents dumped waste in the drain during rainfall. Burning as a form of disposal practice accounted for $8.4 \%$ and $11.5 \%$ in the high and medium densities, respectively. The dumping of waste on open space was a practice found in all the three residential densities. It however accounted for $10.8 \%, 12.5 \%$, and $11.3 \%$ of all the disposal methods in the high, medium, and low residential densities, respectively. The disposal of waste on vacant plots of land was common in places where landholders were yet to develop such land.

It can be deduced from (Table 2) that dumping of waste in run-off water especially during the rainy season was a means of disposal which in the high and medium densities accounted for $16.5 \%$ and $18 \%$ [28]. Study done in one of Ghana cities, Tamale has revealed that $92.2 \%$ of households used waste bins which suggest that most of the people are concerned about hygiene and the need to keep the environment clean; $6.1 \%$ had no specific storage system and therefore disposed their waste directly at a disposal point after collection in the house. This probably accounts for littering of waste around some homes and in the communities. $1.7 \%$ stored waste within the house before disposal later. Of the waste bins that were used by respondents, approximately $59.6 \%$ were plastics and $38.0 \%$ metal. There were also differences in the way in which waste bins were used from one residential area to the other. $51.8 \%$ of the waste bins used were covered and $48.2 \%$ uncovered [29].

\section{Significance of the Study}

The study was conducted to identify the knowledge, attitude and practice of solid and liquid waste management of Mizan -Aman Town .The study hoped that from dissemination of necessary information to different stake holders, knowledge, attitude and practice gap will be filled In addition the study hopped from the information that will be provided, the concerned authorities will intervene to bend the existing and potential problems of the town and furthermore it will serve as source of data for future researchers [30-38].

\section{Objectives}

General Objectives: Assessing knowledge, attitude and practice of Addis and Kometa kebele community towards waste disposal management in South West Ethiopia, 2017.

Specific Objectives: To determine the level of knowledge of liquid and solid waste disposal management among Addis and Kometa kebele community. To determine the attitude of liquid and solid waste disposal managementamong Addis and Kometa kebele community. To determine the practice of liquid and solid waste disposal management among Addis and Kometa kebele community.

\section{Methods and Materials \\ Study Area and Period}

This study was conducted in Addis and Kometa kebele, MizanAman town, Bench-Maji Zone, SNNPR and South West Ethiopia which is found about $568 \mathrm{~km}$ from Addis Ababa and $833 \mathrm{~km}$ from Awasa. According to the central statistical agency of 2008, the population size of Mizan-Aman Town is 48,706 and the total number of household in Mizan-Aman town is 12,824 . The town is known for its diver's ethnicity. Among those Bench, Kefa and Amhara respectively accounts majority numbers. The town has many governmental and private organizations/service providers to the community such as bank, telephone, post office, one University teaching hospital, one health center, one health science college, one university and there are some different levels of private clinic and pharmacy, also the town has KG, elementary, high school, senior secondary and preparatory schools as well as one college of agriculture. Even the town has five kebele, the study was conducted on two selected kebele, namely Addis and Kometa Kebele from April 26-May 07/2017.The total population of the two kebele is 27,684 with total house hold of 5,250.

\section{Populations}

a. Source population: The source population of the study included all house hold in Addis and Kometa kebele.

b. Study population: The study populations were selected house hold of Addis and Kometa kebele.

\section{Inclusion and Exclusion Criteria}

a. Inclusion Criteria: All house hold members whose age was above 18 years and available during the study period 
b. Exclusion criteria: Populations who were excluded from this study were those who could not available in the study period, and those who are not households of Addis and Kometa kebele as well as those who has psychiatric problem.

\section{Sample size and sampling technique}

\section{Sample size determination:}

The sample size is determined using the following formula: -

$\mathrm{n}=\mathrm{Z}^{2} \mathrm{Pq} / \mathrm{d}^{2}$, where: -

$\mathrm{n}=$ sample size

$\mathrm{z}=$ Reliability coefficient for the desired confidence interval (CI) of $95 \%$.

$\mathrm{P}=$ the proportion of population possessing the character of interest.

$q=1-p$ and $d=$ degree of precision=0.05 (allowed probability of error).

Sample size was determined by taking the following assumptions; since there was no previous study in the area, the estimated prevalence rate to be $50 \%$, confidence interval of $95 \%$, margin of error $5 \%$.

Since the study populations number is less than 10,000 and sample size/study population is greater than 0.05 itis calculated by using the following formula with considering adjustment

$$
\mathrm{n}=(1.96)^{2}(0.5)(0.5) /(0.05) 2=384
$$

By considering the none response rate of $10 \%=38.4$ which is approximated to 35 the total sample size is 423 but since sample size to study population is greater than 0.05 , correction formula $(\mathrm{n} / 1+\mathrm{n} / \mathrm{N})$ is used to determine the final sample size which $=423 / 1+423 / 5250=391.45$ approximately 392. Next the value of $\mathrm{k}$ was calculated as $=5250 / 392=13$.

\section{Sampling technique}

Two kebele were selected using simple random sampling(lottery) method but Systematic sampling technique was used to select households included in the study population Then the first house was located by lottery method the next house hold was every total household divided by sampled households that means $\mathrm{k}$ th house hold throughout the study, where $\mathrm{k}$ is the number obtained by above division and its value is 13 .

\section{Variables}

\section{Independent variables}
I. Sex
II. Age
III. Religion
IV. Educational status
V. Ethnicity

\section{Dependent variables}

I. Level of knowledge about liquid and solid waste disposal management.

II. Attitude toward liquid and solid waste disposal management.

III. Practice to ward liquid and solid waste disposal management.

\section{Data Collection Methods and Instruments}

Data was collected by interviewing Mizan-Aman Town community house hold leaders by using structured questionnaire and check list. The questionnaire was prepared in English and translated to Amharic language to ensure clarity. Then data collection task was accomplished by all group members.

\section{Data entry, Processing, Analysis and Presentation}

After collecting, the data was tallied manually, processed and analyzed in a line of its objective using suitable statistical tools by using manual tally and table of frequency.

\section{Data Quality Assurance and Management}

Before the actual data collection, pre- test was conducted to evaluate the appropriateness of the data collection instruments and pretest was performed on $5 \%$ of population else from study area (Hibret Keble). The questioners were checked for completeness, consistency, sensitivity and how much it addresses the objective of the study and then measures was taken to correct the questionnaire accordingly.

\section{Operational Definition}

a. Knowledge: is the concepts and information that study subjects have regarding liquid and solid waste disposal

b. Attitude: is the perception and internal feeling that study subjects have; regarding liquid and solid waste disposal which may be positive or negative.

c. Practice: actions under taken by study subjects on liquid and solid waste management

d. Waste: a useless material or substance produced while making something else

e. Solid Waste: discarded materials other than liquid

f. Liquid waste: can be fluid as waste water, fats, oils or grease, used oil and hazardous house hold liquids.

g. Good knowledge: if $75 \%$ of knowledge questions (3out of 4 ) were responded with equal to or more than $75 \%$ of respondents answered correctly

h. Moderate knowledge: if 50-74.99\% of knowledge questions ( 2 out of 4 ) were responded with equal to or more than $50 \%$ of respondents answered correctly

i. Poor knowledge: if less than $50 \%$ of knowledge questions (less than 2 out of 4 ) were responded with less than $50 \%$ of respondents answered correctly 
j. $\quad$ Positive attitude: if $60 \%$ of attitude question (3 out of 4 ) were responded with equal to or more than $75 \%$ of respondents answered correctly.

k. Negative attitude: if less than $60 \%$ of attitude questions (less than 2 out of 4 ) were responded with less than $50 \%$ of respondents answered correctly.

l. Good practices: if $70 \%$ of fitting practices questions (2 out of 3) was responded with equal to or more than $75 \%$ of respondents correctly.

m. Poor practice: if less than $70 \%$ of fitting practices questions (less than 2 out of 3 ) were responded with less than $50 \%$ of respondents correctly.

\section{Ethical Consideration}

Official letter of cooperation was written from Mizan-Tepi University, department of nursing to the Mizan- Aman Town Municipality. Permission was obtained from municipality and respondents, also the respondents were informed by study conductors about the objective of study as well as confidentiality of their information. The right of the respondents to refuse answering for few or all of the questions was also respected.

\section{Dissemination of the Result}

The final result will be disseminated to Mizan-Tepi University College of Health Science, department of Nursing and MizanAman Municipality as well as it will send for scientific Journal for publication.

\section{Result}

The expected number of participants to respond was 392but only 388 were included in the study which gives $99 \%$ of response rate.

\section{Socio- demographic characteristics}

In this study, nearly half of the respondents 183 (48.6\%) were between 21-30 years. According to the finding majority of respondents 326 (84\%) were females and out of 388 respondents 185 (47.9\%) were orthodox, concerning the ethnicity of respondents only $138(35.5 \%)$ were Bench. Regarding the marital status of the respondent's majority338 (87.1\%) were married ,161 (41.9\%) were merchants in their occupation, the finding of the study also revealed $102(26.3 \%)$ could only write and read as well as, out of 388 respondents majority $310(79.9 \%)$ did not know their monthly income (Table 1).

The finding of this study showed that all respondents $388(100 \%)$ know what waste mean, but they describe waste in different ways; of these $303(78 \%)$ out of 388 respondents define waste as useless materials or dirt. On the other hand, all respondent $388(100 \%)$ already know, solid and liquid wastes unless managed well cause for the generation of different infectious disease but out of 388 respondents majority 196 (50.5\%) did not knew solid wastes can be recycled for further use. Over all the study revealed majority $(81.8 \%)$ of the respondents have good knowledge while the rest $18.2 \%$ have poor knowledge (Table 2).

The attitudes of participants were analyzed as follows: As this study showed that, (77.5\%) of the study participants had positive attitude concerning liquid and solid waste disposal management. At the study period, all of the respondents (100\%) thought that proper waste management has health and economic importance. The finding of the study also showed that more than half of respondents 208(53.6\%) did not accept the idea about every person is responsible for collection and proper disposition of wastes. On the other hand, all respondents believe that liquid and solid wastes must be collected separately as well as majority respondents $(72.1 \%)$ believed that waste should be recycled for further use.

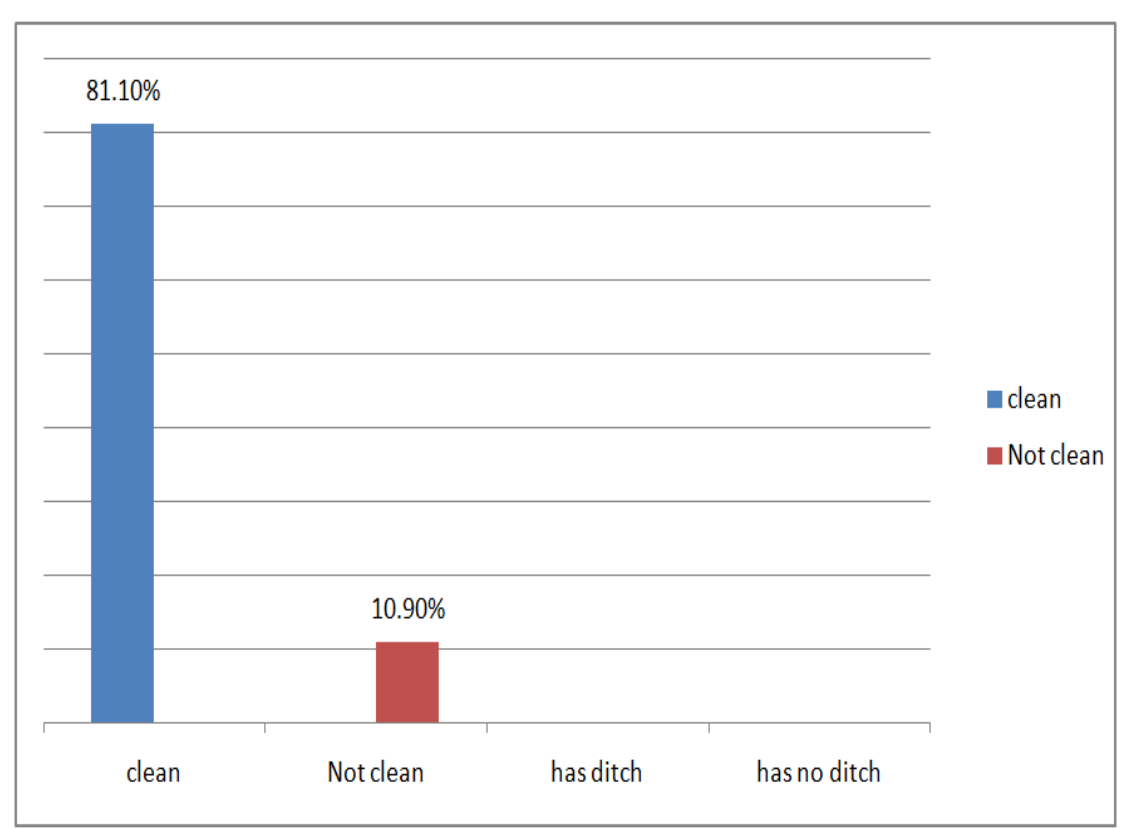

Figure 1: The general condition (cleanliness) of compounds of respondents that was observed during period. 
The practices of the respondents were analyzed as follows:

This study has revealed that $76.9 \%$ respondents show positive attitude while the rest 23.1 showed negative attitude. However, all study participants collect solid and liquid wastes in their compound on daily basis majority (67.8\%) of study population do not properly managed solid and liquid wastes after collection. Concerning the way of managing solid wastes, open dumping accounts for about (27.8\%) (Tables 3 \& 4) (Figure 1).

Table 4: practice assessing questions and their respective answers, Addis and Kometa kebele, June, 2017.

\begin{tabular}{|c|c|c|c|}
\hline & Variables & Frequency & Percentage \\
\hline $\begin{array}{l}\text { Do you collect solid waste in your } \\
\text { compound }\end{array}$ & Yes & 388 & 100 \\
\hline $\begin{array}{l}\text { Do you manage solid and liquid } \\
\text { waste after collection }\end{array}$ & Yes & 388 & 18 \\
\hline \multirow{5}{*}{$\begin{array}{l}\text { If yes for above question how do } \\
\text { you manage solid wastes }\end{array}$} & Burning & 70 & 19.8 \\
\hline & $\begin{array}{c}\text { By taking to waste accumulation } \\
\text { site }\end{array}$ & 77 & 20.6 \\
\hline & By collecting in to the pit & 80 & 13.7 \\
\hline & $\begin{array}{l}\text { By cooperating with kebele } \\
\text { administration }\end{array}$ & 53 & 27.8 \\
\hline & By open dumping & 108 & 30.9 \\
\hline
\end{tabular}

\section{Discussion}

\section{Knowledge}

Knowledge about a given issue has been recognized as one of the major determinants that shape the attitude, and practice of a community. A positive correlation between resident's level of knowledge about issues related to environment and their attitude has been supported by various literatures. Now a day's environmental problems in general and mishandling of wastes in particular are among the leading causes for ill-health and impediments for national development. Improper waste management may have health and environmental hazards. Studies showed the relationship of many diseases to improper waste management. The finding of this study concerning the knowledge level of participants $81.8 \%$ of respondents have good, level of knowledge inconsistent with similar study conducted in Malaysia city that showed $64 \%$ best knowledge level of respondents. The reason for this discrepancy of the finding might be the difference of sample size or period of study or both and the socio-economic difference among the study participants.

The finding also revealed that $(77.5 \%)$ study participants have positive attitude toward waste management nearly to other study which was conducted in Thailand city (92.2\%) [23] While quite different from similar study conducted in Malaysia city that revealed $65.9 \%$ of negative attitude of participant [26]. The possible reason might be the period of study and place or age and sex of participants. The finding of this study showed $76.9 \%$ of participants have good practices to ward waste management. Specifically, this study showed that $27.8 \%$ of respondents practices still open dumping of waste disposal this is inconsistent from similar study conducted in Gweru Zimbabwe that showed 65\% practices of open dumping, the cause might be the presence of health extension workers and period of study [].

Limitation of the Study: Shortage of study period and data collection by principal investigator.

\section{Conclusion}

The finding revealed that Addis and Kometa community have good level of knowledge as well as have positive attitude and have good practice to ward waste management.

\section{Recommendation}

Based on these findings, the following points were recommended:

A. The Mizan-Aman town municipality was recommended to prepare pits/ditches in the town in sufficient quantity for solid waste disposal.

B. Mizan-Aman town community has best knowledge, positive attitude and good practice so Mizan-Aman Municipality should do more to ensure the sustainability of this trend as well as to aware $100 \%$ of community.

C. Further detailed studies were recommended for intervention by using this high light for further interventions.

\section{References}

1. UNICEF (2009) Water, Sanitation and Hygiene.

2. Rabie T, Curtis V (2006) Hand washing and risk of respiratory infections: a quantitative systematicr3eview. Tropical Medicine \& International Health 11(3): 258-267.

3. Solid and liquid waste management Extension package (2004) Federal Democratic Republic of Ethiopia Ministry of Health, Ethiopia.

4. Atlabachew G, Learners (2007) Academic Staffs' Environmental Knowledge, Attitude, Intension and Behavior of Adama. Unpublished MA Thesis submitted to School of Graduate Studies, Addis Ababa University, Ethiopia, p. 15.

5. United Nations Development Programme (UNDP) (2006) Beyond scarcity: power, poverty and the global water crisis. Human Development Report, New York, USA, 25-36.

6. Abebaw D (2008) Determinants of Solid Waste Disposal Practices in Urban Areas of Ethiopia: A Household-Tewodros T Household waste disposal in Mekelle city, Ethiopia. Waste Management 28(10): 2003-12. 
7. Tefera W (2008) Technical Issues of Sanitation and Hygiene in Mirab Abaya and Alaba; a case studyreport from the Southern Nations Region (SNNPR) of Ethiopia. RIPPLE Working p. 2.

8. Legesse W, Haile Mariam D, Kloos H (2006) Water supply and sanitation. In; Berhane Y,Haile MariamD, Kloos H (Eds.), Epidemiology and Ecology of health and disease in Ethiopia pp. 129-146.

9. Unpublished data from census record of the Kersa Demographic Surveillance-Health Research Center 2007.

10. World Health Organization (2003) Combating water borne disease at the house hold level: International net work to promote house hold water treatment and safe storage. Geneva, Switzerland. WHO, 1993. Ministry of water resources. Sanitation and Hygiene issue paper, Ethiopia.

11. Solid waste management (Envh-202) module published (2010) Jimma Ethiopia.

12. Joint Monitoring Programmed for Water Supply \&Sanitation (JMP). Progress on Sanitation and Drinking Water, 2010 Update. UNICEF and WHO 2010: 6-30.

13. Hutton G, Bartram J (2008) Global cost of attaining the Millennium Development Goal for water supply and sanitation. Bulletin of the World Health Organization 86(1): 1-80.

14. Wang C (2008) Health Promotion and Disease Prevention.

15. Journal of Community Health 3(1): 471-91.

16. Tefera W (2008) Technical Issues of Sanitation and Hygiene in Mirab Abaya and Alaba; a case studyreport from the Southern Nations Region (SNNPR) of Ethiopia. RIPPLE Working p. 2.

17. Legesse W, Haile Mariam D, Kloos H (2006) Waters's supply and sanitation. In: Berhane Y, Haile MariamD, Kloos H (Eds.), Epidemiology and Ecology of health and disease in Ethiopia. Shama Books, Ethiopia, pp. 129-146.

18. Unpublished data from census record of the Kersa Demographic Surveillance-Health Research Center, 2007.

19. George T, Hilary T, Samuel A (1993) Evolution of solid waste management. Integrated solid waste management. MC Graw Hill Book Corporation, New York, USA, p. 3-21

20. Puttam Reddy Mamath (2011) Benefits of Teaching Environmental Education on Solid Waste Management for Engineering Students. European Journal of Humanities and Social Sciences 11(1): 1-8.

21. Solomon Cheru (2011) Assessment of Municipal Solid Waste Management Service in Dessie Town. MA thesis, School of Graduate Studies, College of Social Science, Department of Geography and Environmental Studies, Addis Ababa University, Ethiopia.

22. Tadesse Kuma (2004) Dry Waste Management in Addis Ababa City. Accounting for Urban Environment. Ethiopian Development Research Institute. Addis Ababa, Ethiopia.
23. Nigatu (2011) Challenges and Opportunities in Municipal Solid Waste Management. The Case of Addis Ababa City, Central Ethiopian. Institute of Environment, Gender and Development, Hawasa University, Ethiopia.

24. Asmawati Desa, NorBa'yah Abdkadir, Fatimah Yuso of (2012) Environmental Awareness and Education a key Approach to Solid Waste Management. A Case Study of University in Malaysia, Malaysia.

25. Steven Jerie, Daniel Tevera (2014) Solid Waste Management Practices in the Informal Sector of Gweru, Zimbabwe. Journal of Waste Management 2014: 1-14.

26. Ahmeid H (2013) Assessment on awareness of and view about solid waste management among high school students in Gurage zone wolkite town Ethiopia, Ethiopia.

27. Chainarong Apinhapath (2014) Community Mapping and Theory of Planned Behavior as Study Tools for Solid Waste Management. Journal of Waste Management 2014: 1-7.

28. C Trachu (2012) Thailand Pollution Situation Report 2012, Department of Pollution Control, Bangkok, Thailand.

29. Oluwole Samuel Ojewale (2014) Intraurban Analysis of Domestic Solid Waste Disposal Methods in a Sub-Sahara African City. Journal of Waste Management 2014: 1-7.

30. Ibrahim Issahaku, Frank K Nyame, Abdul Kadiri Brimah (2014) Waste Management Strategies in an Urban Setting Example from the Tamale Metropolis, Ghana. Journal of Waste Management 2014.

31. Fetene G, Donald R (2003) A Sanitation Assessment of a rural Ethiopian village. Texas Journalof Rural Realth 21(4): 18-23.

32. Jerry A (2000) Waste water treatment and disposal. Basic environmental technology, water supply, waste management and pollution control $\left(3^{\text {rd }}\right.$ edn). New-Jersey, USA, pp. 227-271.

33. Abebaw D (2008) Determination of solid waste, Disposal practices in urban areas of Ethiopia. A household level Analysis. East Africa social science research review (EASSRR) 24(1).

34. Federal Democratic Republic of Ethiopia Ministry of Health (2004) solid and liquid waste management Extension package, Ethopia.

35. Aklilu Dalelo (2012) Environmental and Sustainability in Ethiopian Education System: Longitudinal Analysis. Leuphana University, Luneburg, German.

36. Zebenay K (2010) The Challenge of Solid Waste Management in Urban Areas. The Case of Debremarkos Town. MA thesis School of Graduate Studies, Addis Ababa University, Ethiopia p. 22.

37. Ahmeid H (2013) assessment on awareness of and view about solid waste management among high school students in Gurage zone wolkite town Ethiopia, Ethiopia.

38. Bettina Sterkele, Chris Zurbrügg (2003) Baseline Study on Water Supply, Sanitation and Solid Waste in Upper Dharamsala, India.

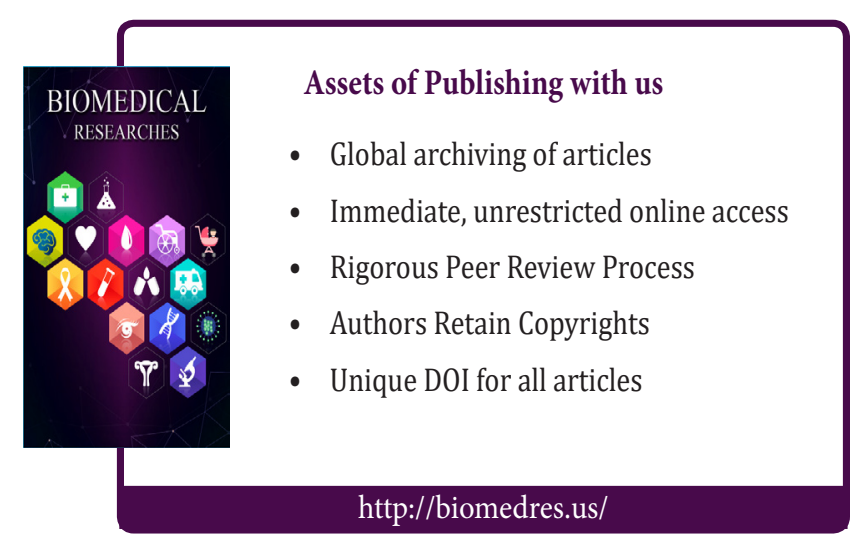

